OPEN ACCESS

Edited by:

Mark Alexander Lever,

ETH Zurich, Switzerland

Reviewed by:

Aude Picard,

Harvard University, USA

Jinjun Kan,

Stroud Water Research Center, USA

${ }^{*}$ Correspondence:

Xiang Xiao

xoxiang@sjtu.edu.cn

Specialty section: This article was submitted to Extreme Microbiology, a section of the journal

Frontiers in Microbiology

Received: 23 May 2016

Accepted: 26 August 2016

Published: 07 September 2016

Citation:

Xiong $L$, Jian $H$, Zhang $Y$ and Xiao $X$ (2016) The Two Sets of DMSO

Respiratory Systems of Shewanella piezotolerans WP3 Are Involved

in Deep Sea Environmental

Adaptation. Front. Microbiol. 7:1418. doi: 10.3389/fmicb.2016.01418

\section{The Two Sets of DMSO Respiratory Systems of Shewanella piezotolerans WP3 Are Involved in Deep Sea Environmental Adaptation}

\author{
Lei Xiong $^{1}$, Huahua Jian ${ }^{1}$, Yuxia Zhang $^{1}$ and Xiang Xiao ${ }^{1,2 *}$
}

'State Key Laboratory of Microbial Metabolism, School of Life Sciences and Biotechnology, Shanghai Jiao Tong University, Shanghai, China, ${ }^{2}$ State Key Laboratory of Ocean Engineering, School of Naval Architecture, Ocean and Civil Engineering, Shanghai Jiao Tong University, Shanghai, China

Dimethyl sulfoxide (DMSO) is an abundant methylated sulfur compound in deep sea ecosystems. However, the mechanism underlying DMSO-induced reduction in benthic microorganisms is unknown. Shewanella piezotolerans WP3, which was isolated from a west Pacific deep sea sediment, can utilize DMSO as the terminal electron acceptor. In this study, two putative dms gene clusters [type I (dmsEFA1B1G1H1) and type \| (dmsA2B2G2H2)] were identified in the WP3 genome. Genetic and physiological analyses demonstrated that both $d m s$ gene clusters were functional and the transcription of both gene clusters was affected by changes in pressure and temperature. Notably, the type I system is essential for WP3 to thrive under in situ conditions $\left(4^{\circ} \mathrm{C} / 20 \mathrm{MPa}\right)$, whereas the type II system is more important under high pressure or low temperature conditions $\left(20^{\circ} \mathrm{C} / 20 \mathrm{MPa}, 4^{\circ} \mathrm{C} / 0.1 \mathrm{MPa}\right)$. Additionally, DMSO-dependent growth conferred by the presence of both $d m s$ gene clusters was higher than growth conferred by either of the dms gene clusters alone. These data collectively suggest that the possession of two sets of DMSO respiratory systems is an adaptive strategy for WP3 survival in deep sea environments. We propose, for the first time, that deep sea microorganisms might be involved in global DMSO/DMS cycling.

Keywords: Shewanella, DMSO respiration, high pressure, low temperature, environmental adaptation

\section{INTRODUCTION}

Dimethyl sulfoxide (DMSO) concentrations in deep oceanic water are higher than $1.5 \mathrm{nM}$ at depths up to $1,500 \mathrm{~m}$ in the equatorial Pacific Ocean and never drop below $1.3 \mathrm{nM}$ at depths up to $4,000 \mathrm{~m}$ in the Arabian Sea (Hatton et al., 1996, 1998, 1999). It is thought to be an environmentally significant compound due to the potential role it plays in the biogeochemical cycle of the climatically active trace gas dimethyl sulfide (DMS; Hatton et al., 2005). DMSO can be produced either through the transformation of DMS by both photooxidation and bio-oxidation routes or by direct production from marine phytoplankton (Hatton et al., 1996; Simó, 1998; Moran et al., 2012). In addition to its roles in protecting cells against photo-generated oxidants and cryogenic damage, DMSO can also be used as an alternative electron acceptor for energy conservation through microbial dissimilatory reduction 
TABLE 1 | Strains and plasmids.

\begin{tabular}{|c|c|c|}
\hline Strain or plasmid & Description & $\begin{array}{l}\text { Reference } \\
\text { source }\end{array}$ \\
\hline \multicolumn{3}{|l|}{ E. coli } \\
\hline WM3064 & Donor strain for conjugation; $\Delta d a p A$ & $\begin{array}{l}\text { Gao et al. } \\
(2006)\end{array}$ \\
\hline \multicolumn{3}{|l|}{ S. piezotolerans WP3 } \\
\hline WT & Wild type strain & Lab stock \\
\hline$\Delta d m s A 1$ & dmsA1 single mutant derived from WT & This study \\
\hline$\Delta d m s A 2$ & dmsA2 single mutant derived from $\mathrm{WT}$ & This study \\
\hline$\Delta \Delta d m s A$ & $\begin{array}{l}d m s A 1 \text { and } d m s A 2 \text { double mutant } \\
\text { derived from } W T\end{array}$ & This study \\
\hline$\Delta d m s B 1$ & dmsB1 single mutant derived from WP3 & This study \\
\hline$\Delta d m s B 2$ & dmsB2 single mutant derived from WP3 & This study \\
\hline$\Delta \Delta d m s B$ & $\begin{array}{l}\text { dmsB1 and } d m s B 2 \text { double mutant } \\
\text { derived from WP3 }\end{array}$ & This study \\
\hline$\Delta \Delta d m s A-d m s A 1-C$ & $\begin{array}{l}\text { Complemented strain of } \Delta \Delta d m s A \\
\text { double mutant }\end{array}$ & This study \\
\hline$\Delta \Delta d m s A-d m s A 2-C$ & $\begin{array}{l}\text { Complemented strain of } \Delta \Delta d m s A \\
\text { double mutant }\end{array}$ & This study \\
\hline$\Delta \Delta d m s A-p S W 2$ & $\begin{array}{l}\Delta \Delta d m s A \text { double mutant containing the } \\
\text { empty pSW2 vector as negative control }\end{array}$ & This study \\
\hline$\Delta \Delta d m s B-d m s B 1-C$ & $\begin{array}{l}\text { Complemented strain of } \Delta \Delta d m s B \\
\text { double mutant }\end{array}$ & This study \\
\hline$\Delta \Delta d m s B-d m s B 2-C$ & $\begin{array}{l}\text { Complemented strain of } \Delta \Delta d m s B \\
\text { double mutant }\end{array}$ & This study \\
\hline$\Delta \Delta d m s B-p S W 2$ & $\begin{array}{l}\Delta \Delta d m s B \text { double mutant containing the } \\
\text { empty pSW2 vector as negative control }\end{array}$ & This study \\
\hline \multicolumn{3}{|l|}{ Plasmid } \\
\hline pSW2 & $\begin{array}{l}\text { Chloramphenicol resistance, generated } \\
\text { from filamentous bacteriophage SW1; } \\
\text { used for complementation }\end{array}$ & $\begin{array}{l}\text { Yang et al. } \\
\text { (2015) }\end{array}$ \\
\hline pSW2-dmsA1 & $\begin{array}{l}\text { pSW } 2 \text { containing } d m s A 1 \text { and the } \\
\text { promoter region of } d m s A 2\end{array}$ & This study \\
\hline pSW2-dmsA2 & $\begin{array}{l}\text { pSW2 containing } d m s A 2 \text { and its own } \\
\text { promoter region }\end{array}$ & This study \\
\hline pSW2-dmsB1 & $\begin{array}{l}\text { pSW2 containing } d m s B 1 \text { and the } \\
\text { promoter region of } d m s B 2\end{array}$ & This study \\
\hline pSW2-dmsB2 & $\begin{array}{l}\text { pSW2 containing } d m s B 2 \text { and its own } \\
\text { promoter region }\end{array}$ & This study \\
\hline pRE112 & $\begin{array}{l}\text { Chloramphenicol resistance, suicide } \\
\text { plasmid with sacB1 gene as a negative } \\
\text { selection marker; used for gene } \\
\text { deletion }\end{array}$ & Lab stock \\
\hline $\mathrm{pRE} 112-\Delta d m s A 1$ & $\begin{array}{l}\text { pRE112 containing the PCR fragment } \\
\text { for deleting } d m s A 1\end{array}$ & This study \\
\hline $\mathrm{pRE} 112-\Delta d m s A 2$ & $\begin{array}{l}\text { pRE112 containing the PCR fragment } \\
\text { for deleting } d m s A 2\end{array}$ & This study \\
\hline $\mathrm{pRE} 112-\Delta d m s B 1$ & $\begin{array}{l}\text { pRE112 containing the PCR fragment } \\
\text { for deleting } d m s B 1\end{array}$ & This study \\
\hline $\mathrm{pRE} 112-\Delta d m s B 2$ & $\begin{array}{l}\text { pRE112 containing the PCR fragment } \\
\text { for deleting } d m s B 2\end{array}$ & This study \\
\hline
\end{tabular}

RT-PCR, reverse transcription-PCR.

(Sunda et al., 2002; Asher et al., 2011). Although DMSO acts as the dominant organic sulfur compound in deep oceanic water, the mechanism underlying DMSO bio-reduction by bathypelagic microorganisms is unknown.

Biochemical and genetic analyses of anaerobic DMSO respiration have been performed, particularly in Escherichia coli
(McCrindle et al., 2005). In E. coli, two sets of operons are involved in DMSO respiration: the $d m s A B C$ operon and the $y n f E F G H I$ operon, which is a paralog of the former and is likely to be phenotypically silent (Lubitz and Weiner, 2003). The $d m s A B C$ operon encodes the three functional proteins DmsA (the molybdopterin cofactor-containing subunit of the DMSO reductase), DmsB (the ion-sulfur subunit), and DmsC (the NapC-like integral membrane anchor). These three subunits constitute a functional DMSO reductase that is anchored to the periplasmic side of the inner membrane by $\mathrm{DmsC}$. The electron released by menaquinol $\left(\mathrm{MQH}_{2}\right)$ oxidation by $\mathrm{DmsC}$ is transferred via a series of [4Fe-4S] clusters in DmsB to the catalytic subunit DmsA, which reduces DMSO to DMS (Stanley et al., 2002).

Shewanella is a genus of facultative anaerobic, Gramnegative microorganisms that are widely distributed in marine and freshwater environments. The hallmark of Shewanella is their ability to utilize a broad range of terminal electron acceptors, which makes them outstanding candidates for potential applications in the bioremediation of pollutants (Nealson and Scott, 2006; Hau and Gralnick, 2007). In Shewanella species, the DMSO reduction pathway has been characterized only in Shewanella oneidensis MR-1, which was isolated from the sediment of Oneida Lake in New York (Venkateswaran et al., 1999). Two $d m s$ operons were found in the MR-1 genome, although only one of them mediated DMSO reduction under the tested conditions (Gralnick et al., 2006; Fredrickson et al., 2008).

Shewanella piezotolerans WP3 was isolated from a west Pacific deep sea sediment at a depth of 1,914 m (Wang et al., 2004; Xiao et al., 2007). Our previous study demonstrated that WP3 was able to utilize DMSO as a terminal electron acceptor for anaerobic growth (Xiao et al., 2007). However, the precise mechanism of anaerobic DMSO respiration by WP3 is still unknown. In this study, we showed that WP3 contained two dms gene clusters (type I and type II), both of which were functional; type I was essential for the ability of WP3 to thrive under in situ conditions $\left(4^{\circ} \mathrm{C} / 20 \mathrm{MPa}\right)$ and type II was more important under other extreme conditions (i.e., $20^{\circ} \mathrm{C} / 20 \mathrm{MPa}$ or $4^{\circ} \mathrm{C} / 0.1 \mathrm{MPa}$ ). The possession of two sets of DMSO respiratory systems is suggested to be an adaptive strategy for WP3 to cope with extreme deep sea environments.

\section{MATERIALS AND METHODS}

\section{Bacterial Strains and Growth Conditions}

The bacterial strains used in this study are listed in Table 1. E. coli strain WM3064 was routinely grown in Luria Broth medium at $37^{\circ} \mathrm{C}$ with the addition of $500 \mu \mathrm{M}$ 2,6-diaminopimelic acid (Sigma-Aldrich, St. Louis, Mo, USA). For aerobic growth, the S. piezotolerans WP3 strains were cultured in 2216E broth (Wang et al., 2008; Chen et al., 2011) with minor modifications (5 $\mathrm{g} \mathrm{l}^{-1}$ tryptone, $1 \mathrm{~g} \mathrm{l}^{-1}$ yeast extract, and $\left.34 \mathrm{~g} \mathrm{l}^{-1} \mathrm{NaCl}\right)$ at $20^{\circ} \mathrm{C}$ in a rotary shaker at $200 \mathrm{rpm}$. If necessary, chloramphenicol was added to both media $\left(30 \mu \mathrm{g} \mathrm{ml}^{-1}\right.$ for E. coli strains and $10 \mu \mathrm{g} \mathrm{ml}^{-1}$ for WP3 strains). For the anaerobic growth assay, 
the cultivation of WP3 strains was performed in 2216E broth supplemented with $20 \mathrm{mM}$ lactate and $25 \mathrm{mM}$ DMSO (Burns and DiChristina, 2009). Serum bottles each containing $100 \mathrm{ml}$ of fresh medium were prepared anaerobically by flushing with nitrogen gas through the butyl rubber stopper fixed with a metal seal to strip the dissolved oxygen prior to autoclave sterilization. To examine the growth of the WP3 strains at high hydrostatic pressure, each culture was grown to stationary phase in $2216 \mathrm{E}$ medium at $1 \mathrm{~atm}(1 \mathrm{~atm}=0.101 \mathrm{MPa})$ and $20^{\circ} \mathrm{C}$ in a rotary shaker. The late-log phase cultures were diluted into the same medium to an optical density of 0.3 at $600 \mathrm{~nm}$. Aliquots of the diluted culture $(1 \mathrm{ml})$ were injected into serum bottles containing $100 \mathrm{ml}$ of anaerobic medium through the butyl rubber stopper. After brief shaking, $2.5 \mathrm{ml}$ disposable syringes were used to distribute the culture in $2 \mathrm{ml}$ aliquots. The syringes with needles were stuck into rubber stoppers in a vinyl anaerobic airlock chamber (Coy Laboratory Products Inc., Grass Lake, MI, USA). Then, the syringes were incubated at a hydrostatic pressure of $20 \mathrm{MPa}$ at $4^{\circ} \mathrm{C}$ or $20^{\circ} \mathrm{C}$ in stainless steel vessels (Feiyu Science and Technology Exploitation Co., Ltd, Nantong, China) that could be pressurized using water and a hydraulic pump. These systems were equipped with quick-connect fittings for rapid decompression and recompression (Yayanos and Van Boxtel, 1982; Allen et al., 1999).

\section{Deletion Mutagenesis and Complementation in S. piezotolerans WP3}

In-frame deletion mutagenesis of $d m s A 1$ (swp3459) was performed as previously reported (Chen et al., 2011). The primers designed to amplify PCR products for mutagenesis are summarized in Supplementary Table S1. To construct a $d m s A 1$ in-frame deletion mutant, two fragments flanking $d m s A 1$ were amplified by PCR. Fusion PCR products were generated using the amplified PCR fragments as templates with primers swp3459-UF and swp3459-DR. After digestion with the restriction enzymes $S m a \mathrm{I}$ and $\mathrm{XbaI}$, the treated fusion PCR products were ligated into the SmaI and XbaI sites of the suicide plasmid pRE112 (Edwards et al., 1998), resulting in the mutagenesis vector pRE112- $\Delta d m s A 1$. This vector was first introduced into E. coli WM3064 and then conjugated into WP3-WT (wild type). Positive exconjugants were spread onto marine agar $2216 \mathrm{E}$ plates supplemented with $10 \%(\mathrm{w} / \mathrm{v})$ sucrose. The chloramphenicol-sensitive and sucrose-resistant colonies were screened by PCR for the $d m s A 1$ deletion. The same strategy was used to construct $\triangle d m s A 2$ single mutants. The double mutant $\triangle d m s A 1 \Delta d m s A 2(\Delta \Delta d m s A)$ was constructed by introducing pRE112-dmsA2 into $\triangle d m s A 1$. To construct the complemented strain of $\Delta d m s A 1 \Delta d m s A 2$, the intact $d m s A 1$ and $d m s A 2$ gene fragments were amplified from the WT genomic DNA. The resulting PCR products were inserted into the shuttle vector pSW2, which was developed from the filamentous phage SW1 of WP3 (Yang et al., 2015). Transformants $\Delta \Delta d m s A$ $d m s A 1-C$ and $\Delta \Delta d m s A-d m s A 2-C$ were obtained by introducing the recombinant plasmids pSW2-dmsA1 and pSW2-dmsA2, respectively, into the $\Delta \Delta d m s A$ strain via conjugation.

\section{RNA Extraction and Reverse Transcription}

Total RNA was extracted from the WP3 strains as previously described (Wang et al., 2009). Briefly, cells in mid-log phase were harvested by centrifugation and treated with the TRI Reagent RNA/DNA/protein isolation kit (Molecular Research Center, Inc., Cincinnati, OH, USA) according to the manufacturer's instructions. Then, the RNA samples were treated with DNase I (Thermo Fisher, Waltham, MA, USA) to remove residual genomic DNA and quantified using the NanoDrop 2000 spectrophotometer (Thermo Fisher, Waltham, MA, USA), followed by reverse transcription reaction with the RevertAid First Strand cDNA Synthesis Kit (Fermentas, Glen Burnie, MD, USA) to obtain cDNA.

\section{Real-time PCR (RT-PCR)}

Primer pairs (Supplementary Table S1) for the genes selected for the RT-PCR analysis were designed using the Primer Express 3.0 software (Applied Biosystems, Warrington, UK). Transcription assays were performed using the 7500 System SDS software in reaction mixtures with total volumes of $20 \mu \mathrm{l}$ containing $10 \mu \mathrm{l}$ of SYBR Green PCR Master Mix (Applied Biosystems, Warrington, $\mathrm{UK}), 0.5 \mu \mathrm{M}$ of each primer, and $1.2 \mu \mathrm{l}$ of the cDNA template. The amount of target was normalized to the reference gene swp2079 (Li et al., 2008; Wang et al., 2009). The RT-PCR assays were performed in triplicate for each sample and a mean value and standard deviations were calculated for the relative RNA expression levels.

\section{DMSO Concentration Determination}

Aliquots $(1 \mathrm{ml})$ of the culture recovered at different time points were filtered immediately through $0.22 \mu \mathrm{m}$ Millex-GP filters (Millipore, Carrigtwohill, Ireland) and stored at $-70^{\circ} \mathrm{C}$ prior to use. The DMSO concentration was determined as previously reported (Cheng et al., 2013). Briefly, the samples were applied for analysis by an Agilent 1200 series high-performance liquid chromatography (HPLC) system (Agilent Technologies, Santa Clara, CA, USA) with a diode-array detector set at $210 \mathrm{~nm}$. DMSO was separated using an Aminex HPX-87H column (BioRad, Hercules, CA, USA) at $50^{\circ} \mathrm{C}$ using $\mathrm{H}_{2} \mathrm{SO}_{4}(5 \mathrm{mM})$ as the

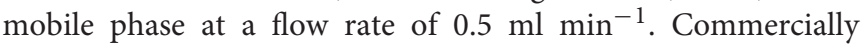
available DMSO (Sigma-Aldrich, St. Louis, MO, USA) was used to generate a calibration curve to estimate the DMSO concentration.

\section{RESULTS}

\section{Determination of the Optimum DMSO Concentration for WP3 Anaerobic Respiration}

The 2216E medium supplemented with sodium lactate and DMSO was used to study the anaerobic DMSO respiration of WP3. The time course of the DMSO concentration was monitored by assessing the cell density (represented by $\mathrm{OD}_{600}$ ) in the medium (Figure 1). The maximum growth was observed 


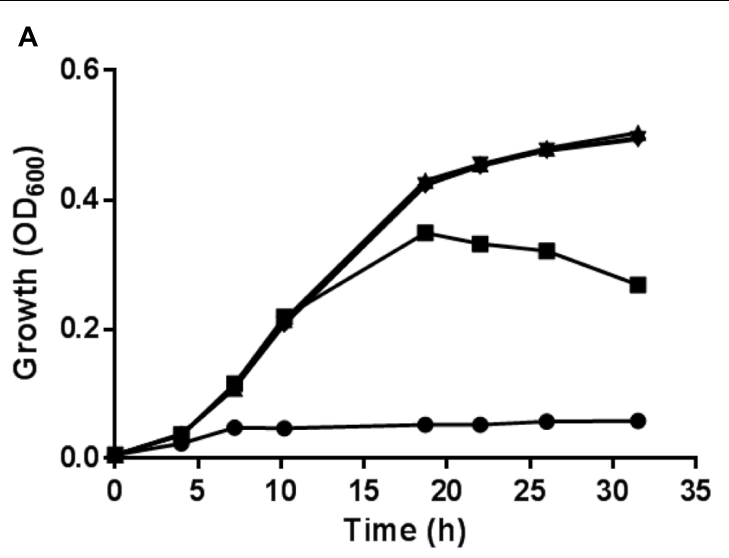

B

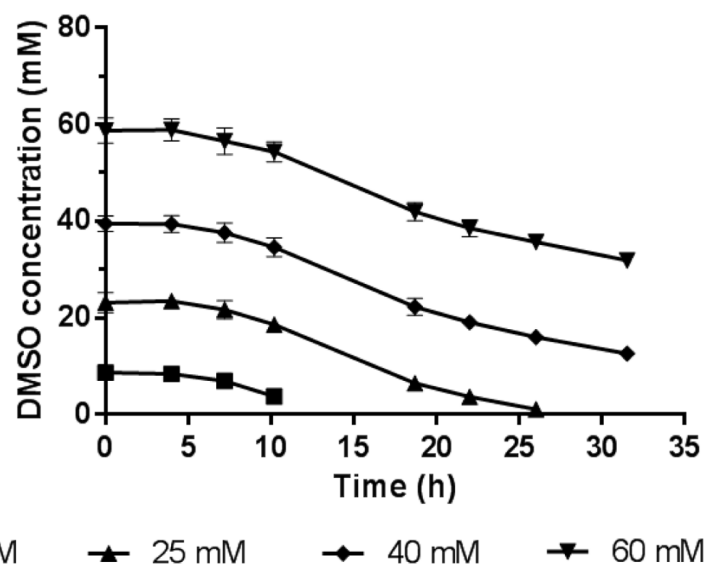

FIGURE 1 | (A) Growth of S. piezotolerans WP3 in 2216E medium using different DMSO concentrations as the sole electron acceptor. (B) Time course of DMSO consumption by S. piezotolerans WP3. The data shown represent the results of two independent experiments and the error bars represent standard deviations of the averages of triplicate cultures.

at a DMSO concentration of $25 \mathrm{mM}$, at which concentration the DMSO in the medium was exhausted and the cells were entering stationary phase. We found no significant differences in the cell density and DMSO consumption with a further increase in the DMSO concentration ( 40 or $60 \mathrm{mM}$ ) compared with growth at the $25 \mathrm{mM}$ concentration, suggesting that excess DMSO (40 or $60 \mathrm{mM}$ ) had no positive effect on the growth yield. Therefore, the subsequent physiological experiments were performed with DMSO at a concentration of $25 \mathrm{mM}$.

\section{Organization of the dms Gene Clusters in WP3}

Two sets of $d m s$ gene clusters [type I (dmsEFA1B1G1H1 and swp3461-swp3456) and type II (dmsA2B2G2H2 and swp0724swp0728)] were identified according to the WP3 genome annotation (Figure 2A). The type I $d m s$ gene cluster matches the archetypal $d m s E F A B G H$ organization. However, no $d m s E$ or $d m s F$ homologous gene was found upstream of $d m s A 2 B 2 G 2 \mathrm{H} 2$ in the type II $d m s$ gene cluster. Additionally, two partially overlapped genes encoding the LysR family regulator were located directly upstream of $d m s A 2$. To investigate whether these two operons were truly polycistronic, reverse transcription PCR was performed to amplify the intergenic regions of neighboring genes. Our data demonstrated that five genes (dmsEFA1B1G1) in the type I $d m s$ gene cluster were co-transcribed, with the exception of swp3456 (Figure 2B). For the type II $d m s$ gene cluster, four genes ( $d m s A 2 B 2 G 2 H 2)$ were co-transcribed as a single operon (Figure 2C).

\section{Both dms Gene Clusters in WP3 Were Functional in DMSO Respiration}

To test whether both $d m s$ gene clusters were responsible for DMSO respiration, we initially monitored the transcription of both $d m s$ gene clusters using quantitative reverse transcription PCR (qRT-PCR). The results showed that both gene clusters were significantly induced under anaerobic DMSO conditions (Supplementary Figure S1). Because $d m s A$ encodes the large catalytic subunit of the DMSO reductase and plays an essential role in DMSO respiration (Trieber et al., 1996), $d m s A$ of these two gene clusters was inactivated and in-frame deletion mutants were constructed. The growth assay performed at $20^{\circ} \mathrm{C} / 0.1 \mathrm{MPa}$ demonstrated that the single mutants $\triangle d m s A 1$ and $\triangle d m s A 2$ retained the ability to use DMSO for anaerobic growth, whereas the double mutant $\Delta \Delta d m s A$ (namely $\Delta d m s A 1 \Delta d m s A 2$ ) failed to grow in the same medium (Figure 3A) and did not consume DMSO (Figure 3B). To confirm that the loss of DMSO-dependent growth of $\Delta \Delta d m s A$ was caused by the disruption of $d m s A 1$ and $d m s A 2$, two complemented strains ( $\Delta \Delta d m s A-d m s A 1-C$ and $\Delta \Delta d m s A-d m s A 2-C$ ) were generated. As expected, the introduction of either $d m s A 1$ or $d m s A 2$ into $\Delta \Delta d m s A$ partially restored the ability of the double mutant to utilize DMSO for anaerobic growth (Figures 3C,D). Because $d m s B$ encoded the small ion-sulfur subunit of the DMSO reductase, we constructed corresponding in-frame deletion mutants $(\Delta d m s B 1, \Delta d m s B 2$, and $\Delta d m s B 1 \Delta d m s B 2)$ and complemented strains $(\Delta \Delta d m s B-d m s B 1-C$ and $\Delta \Delta d m s B-$ $d m s B 2-C)$. Similar results were observed in the growth yields and DMSO consumption of these strains (Supplementary Figure S2). Taken together, these data indicated that both the type I and type II $d m s$ gene clusters were responsible for DMSO respiration.

\section{Transcription of the Two dms Gene Clusters Was Affected by Pressure and Temperature Changes}

To evaluate whether these two $d m s$ gene clusters were involved in DMSO respiration at different temperatures $\left(4\right.$ and $20^{\circ} \mathrm{C}$ ) and pressures $(0.1$ and $20 \mathrm{MPa})$, relative transcription assays of these two clusters were performed by qRT-PCR. The cells were incubated in anaerobic DMSO medium under different growth 
A

Type I

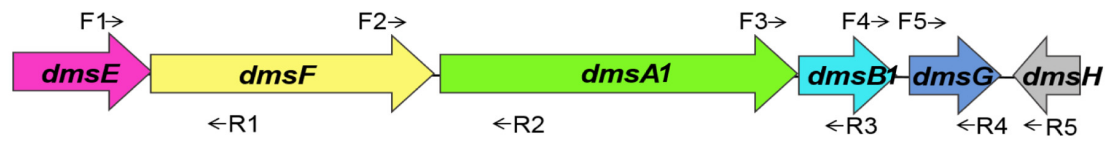

Type II

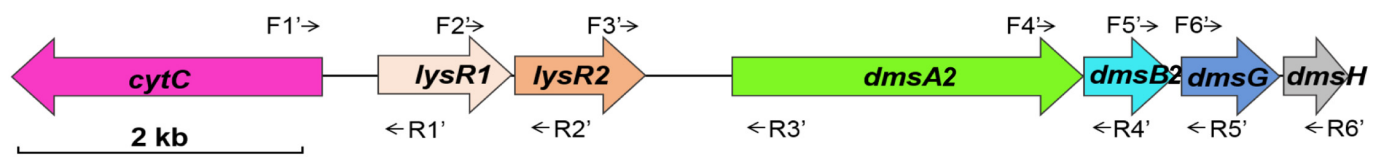

B

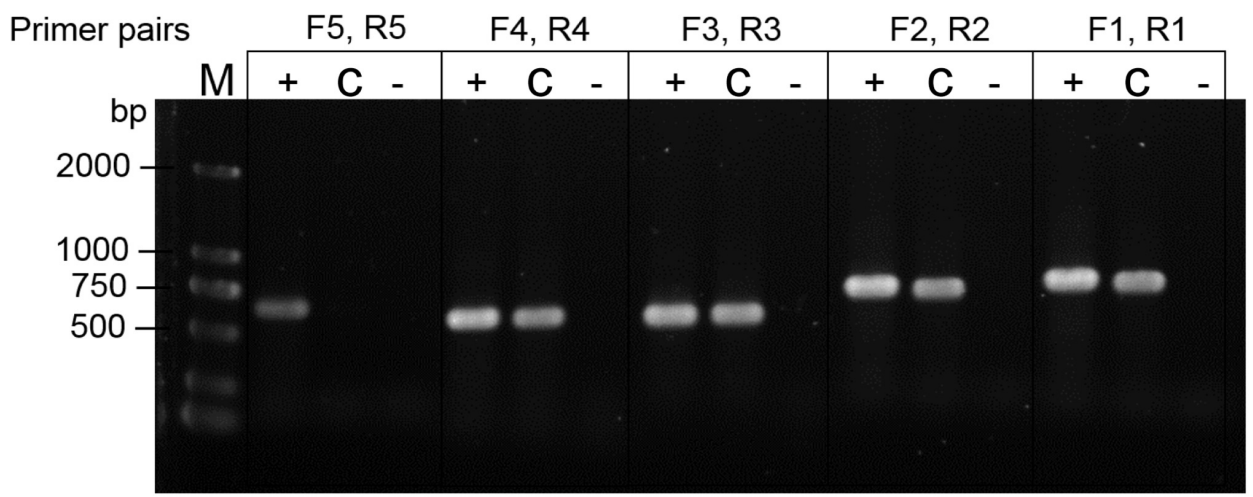

C

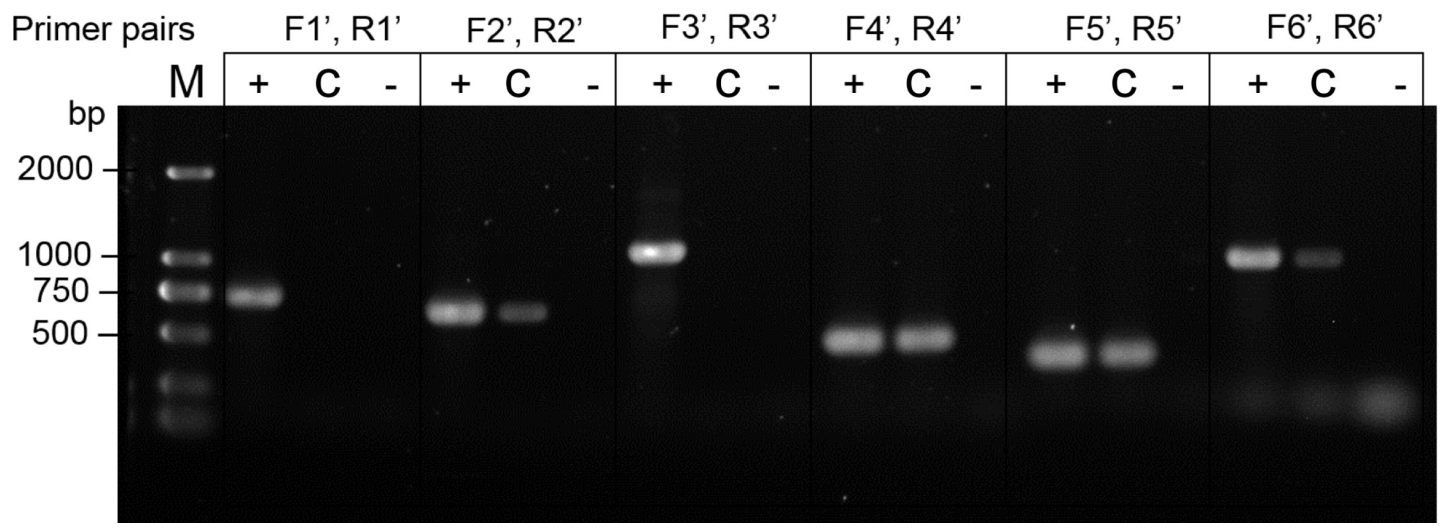

FIGURE 2 | Co-transcriptional analysis of the type I and type II dms gene operons in S. piezotolerans WP3. (A) The operon organization of the two dms gene clusters. Arrows indicate primer pairs spanning adjacent genes used for the co-transcription analysis. (B) Co-transcriptional analysis of the type I gene operon (dmsEFA1B1G1H1). (C) Co-transcriptional analysis of the type II gene operon (dmsA2B2G2H2). The different templates used for each co-transcription confirmation are presented as follows: +, WP3 genomic DNA (positive control); -, distilled water (negative control); and C, WP3 cDNA. The primer pairs used in each assay are indicated as follows: dmsE-F For/Rev (F1, R1); dmsF-A1 For/Rev (F2, R2); dmsA1-B1 For/Rev (F3, R3); dmsB1-G1 For/Rev (F4, R4); dmsG1-H1 For/Rev (F5, R5); cytC-lysR1 For/Rev (F1', R1'); lysR1-R2 For/Rev (F2', R2'); lysR2-dmsA2 For/Rev (F3', R3'); dmsA2-B2 For/Rev (F4', R4'); dmsB2-G2 For/Rev (F5', R5'); and dmsG2-H2 For/Rev (F6', R6'). The resulting amplicons were analyzed by electrophoresis using 1.0\% agarose gels with GelRed staining.

conditions for RNA extraction. Compared to the expression levels of the two $d m s$ gene clusters at $20^{\circ} \mathrm{C} / 0.1 \mathrm{MPa}$, the expression of the type I cluster was significantly down-regulated with pressure increased from atmospheric pressure $(0.1 \mathrm{MPa})$ to high pressure (10 and $20 \mathrm{MPa}$ ) conditions, whereas the expression of type II cluster was significantly up-regulated under the same conditions (Figure 4A). In contrast, the expression profiles of two $d m s$ gene clusters at $10^{\circ} \mathrm{C}$ were generally similar regardless of pressure changes (Figure 4B). Interestingly, the expression profiles of type I $d m s$ clusters at $4^{\circ} \mathrm{C}$ were significantly induced with pressure increased from atmospheric pressure to high pressure (10 and $20 \mathrm{MPa}$ ) conditions, whereas the expression profiles of type II $d m s$ clusters were greatly reduced under the same conditions (Figure 4C). Collectively, these data suggested that the transcription of the two $d m s$ clusters was regulated in response to pressure and temperature changes. 


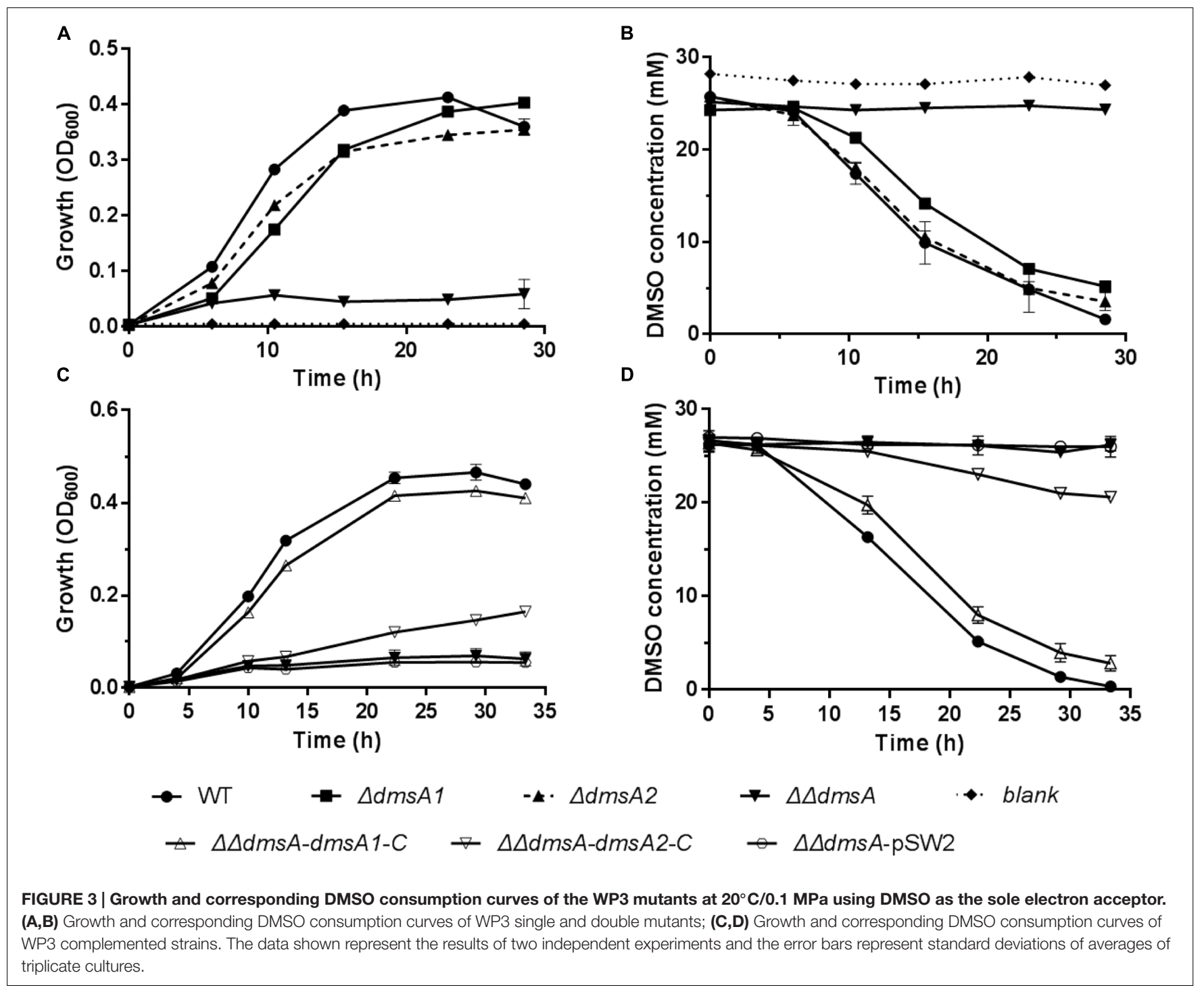

\section{The Contribution of the Two dms Gene Clusters to WP3 Growth was Influenced by Pressure and Temperature}

To investigate whether the two $d m s$ gene clusters were involved in deep sea environmental adaptation, a growth assay was performed at different pressures and temperatures. As predicted, $\triangle d m s A 1$ exhibited a higher growth yield than $\triangle d m s A 2$ when the growth temperature decreased from 20 to $4^{\circ} \mathrm{C}$ or the pressure increased from 0.1 to $20 \mathrm{MPa}$ (Figures $\mathbf{5 A}, \mathbf{C}$ ), which indicated that the type II $d m s$ operon was more important than the type I operon at low temperature or high pressure. Additionally, culture media collected at different time points were filtered and then analyzed to assess DMSO consumption by these strains. The HPLC results indicated that the $\triangle d m s A 1$ mutant exhibited higher DMSO consumption (Figures $\mathbf{5 B}, \mathbf{D}$ ) than $\triangle d m s A 2$ at $4^{\circ} \mathrm{C} / 0.1 \mathrm{MPa}$ or $20^{\circ} \mathrm{C} / 20 \mathrm{MPa}$.

Interestingly, when these strains were incubated at $4^{\circ} \mathrm{C} / 20 \mathrm{MPa}$, the growth of $\triangle d m s A 2$ appeared to be higher than $\triangle d m s A 1$ (Figure 5E), which was consistent with the more efficient DMSO consumption by $\triangle d m s A 2$ in the medium (Figure 5F). Additionally, our results showed that the DMSOdependent growth yield conferred by the presence of the two $d m s$ operons was higher than the growth yield conferred by either of the two dms operons alone, indicating that the presence of both $d m s$ operons was essential for the DMSO-dependent growth of WP3 under in situ deep sea conditions.

\section{DISCUSSION}

DMSO and DMS are interchangeable substrates in marine environments through the bio-reduction and bio-oxidation pathways (Bürgmann et al., 2007; Muyzer and Stams, 2008; Rellinger et al., 2009; Spiese et al., 2009). As a volatile antigreenhouse gas, DMS plays an important climatic role in cloud nucleation and hence may influence the global temperature (Charlson et al., 1987; Andreae, 1990; Curson et al., 2011). 


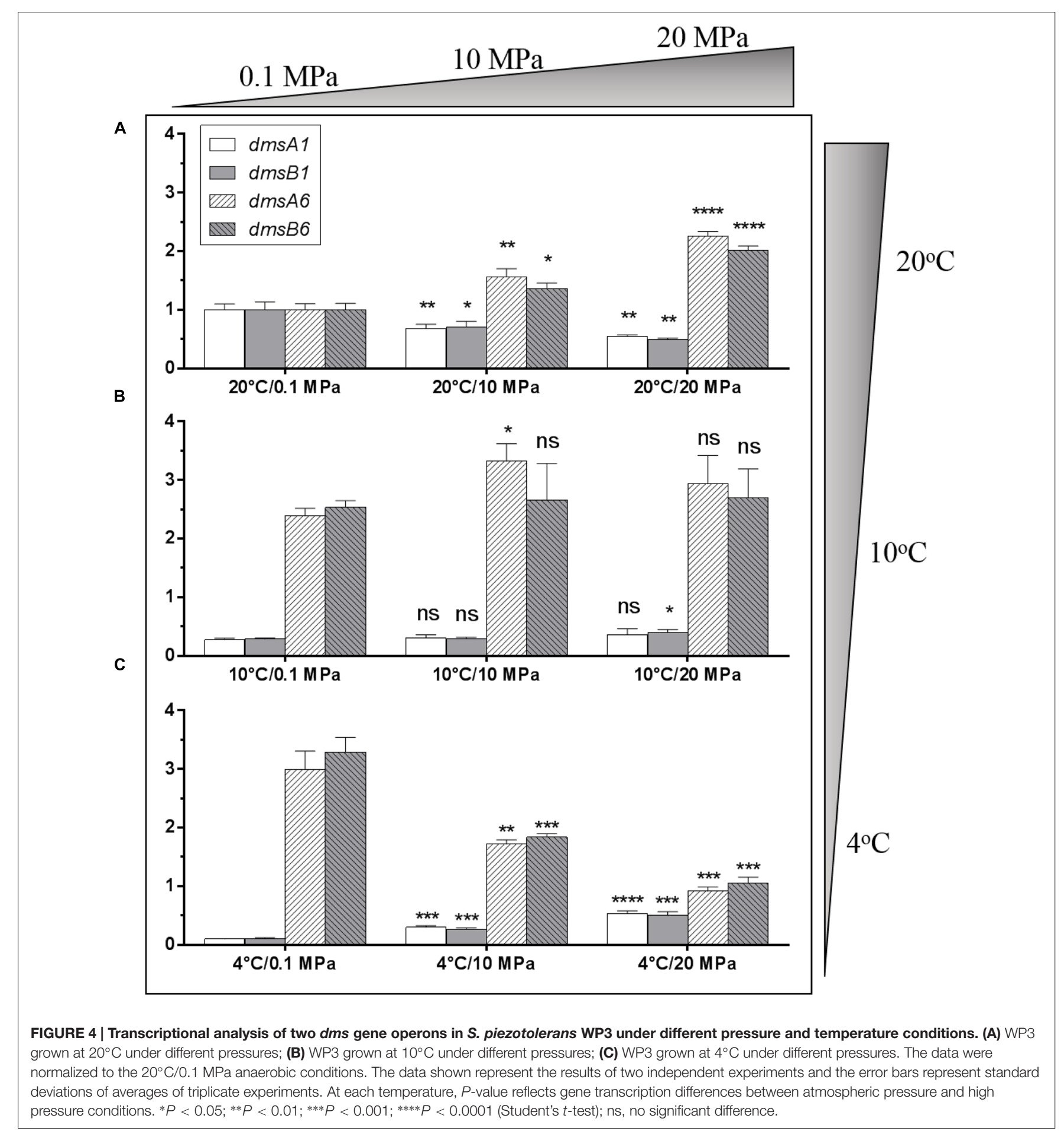

Previous study demonstrated that DMSO as a substantial sink or source for DMS (Hatton et al., 1996). The formation of DMSO would therefore lead to the removal of DMS from sea water, effectively limiting the quantity of DMS available for releasing into the atmosphere (Hatton et al., 2005). Although DMSO has been detected in abyssal ocean water (Hatton et al., 1999), few data are available on the turnover mechanisms of DMSO in deep sea environments. In this study, our results demonstrate a previously unrecognized role for biotic DMSO reduction as an important pathway of DMS production in the deep sea environment.

In the abyssal ocean, metabolic energy is harnessed from the coupling of redox reactions (Orcutt et al., 2011). Microorganisms exploit the available chemical energy by developing strategies 


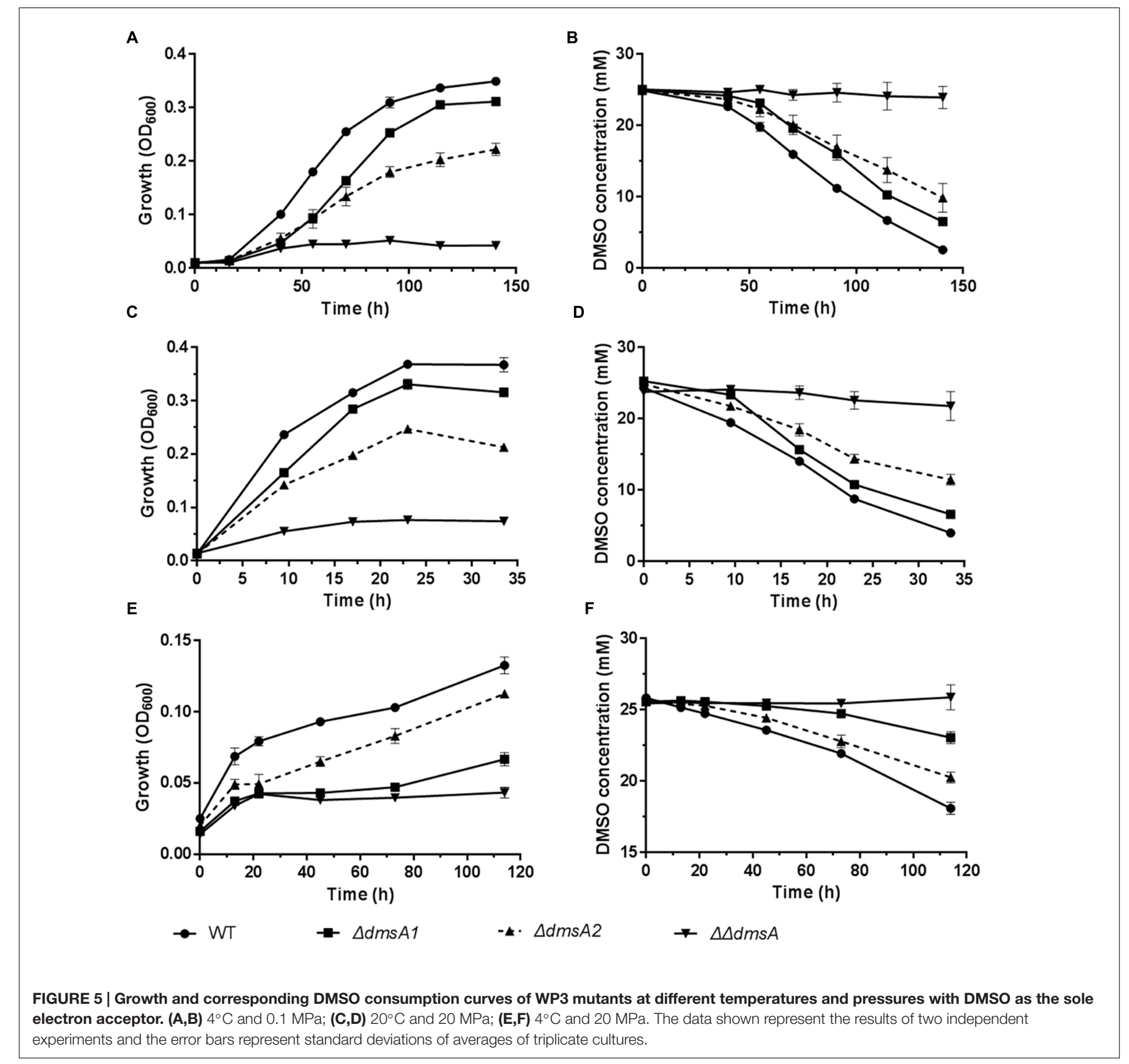

to overcome the activation energy of reaction. The metabolic activities of microorganisms in such environment depend on the availability and speciation of electron donors and acceptors (Froelich et al., 1979). As for DMSO, the $E_{0}{ }^{\prime}$ value for its reduction $(+160 \mathrm{mV})$ lies between those for fumarate/succinate $(+33 \mathrm{mV})$ and nitrate/nitrite $(+433 \mathrm{mV}$; Thauer et al., 1977 ; Wood, 1981), and thus the coupling of DMSO reduction to ATP synthesis presents no energetic difficulty. Accordingly, some culturable bacteria isolated from marine environments have also shown the ability to grow by anaerobic DMSO respiration (Jonkers et al., 1996; Süß et al., 2008). Although sulfate is the most abundant oxidized sulfur species in the dark ocean (Orcutt et al., 2011), the reduction of sulfate yields less energy than that of DMSO, and DMSO could therefore be consumed preferentially.

In Shewanella species, the DMSO reduction pathway was first characterized in S. oneidensis MR-1, which was a strain isolated from the sediment of Oneida Lake in New York (Venkateswaran et al., 1999). Two $d m s$ operons were found in the MR-1 genome; however, only one dms operon mediated DMSO reduction under the tested conditions (Gralnick et al., 2006). In contrast to the results in MR-1, both $d m s$ gene operons in WP3 were functional (Figure 3). Moreover, our results demonstrated that the presence of both operons was essential for the maximum growth of WP3 using DMSO as the sole electron acceptor (Figure 5). Type I matches the archetypal $d m s E F A B G H$ organization, which enables 
the DMSO reductase to localize to the outer membrane of Shewanella and allows the cells to respire DMSO more efficiently (Gralnick et al., 2006). Additionally, type I plays a dominant role in the DMSO-dependent growth of WP3 under in situ deep sea conditions $\left(4^{\circ} \mathrm{C} / 20 \mathrm{MPa}\right)$. Type II is more similar to E. coli (dmsABC organization; Stanley et al., 2002) and may locate in the periplasmic space. The physiological analysis indicated that type II was more important for DMSO-dependent growth than type I under some stressful conditions (i.e., $20^{\circ} \mathrm{C} / 20 \mathrm{MPa}$ and $\left.4^{\circ} \mathrm{C} / 0.1 \mathrm{MPa}\right)$.

To evaluate the impact of the two DMSO respiration systems on growth, we calculated the DMSO consumption of the WP3 mutants by standardizing the growth yield to the same cell density $\left(1\right.$ OD unit $\approx 1.5 \times 10^{8}$ cells; Supplementary Figure S3). Our data showed that WT (type I and type II together) and $\Delta d m s A 1$ (type II alone) required less DMSO than $\Delta d m s A 2$ (type I alone) to reach the same growth yield when incubated at $20^{\circ} \mathrm{C} / 0.1 \mathrm{MPa}, 4^{\circ} \mathrm{C} / 0.1 \mathrm{MPa}$, or $20^{\circ} \mathrm{C} / 20 \mathrm{MPa}$, indicating that type II was a more efficient DMSO respiration system at atmospheric pressure or $20^{\circ} \mathrm{C}$. However, when the WP3 mutants were incubated at $4^{\circ} \mathrm{C} / 20 \mathrm{MPa}, \Delta d m s A 2$ (type I alone) inversely required less DMSO than $\triangle d m s A 1$ (type II alone), indicating that type I was more efficient than type II under the $4^{\circ} \mathrm{C} / 20 \mathrm{MPa}$ in situ condition. Collectively, our results suggest that the possession of multiple systems with similar functions might be an adaptive strategy for bacteria to cope with extreme deep sea environments. Similar adaptive mechanisms can also be found in other deep seaderived Shewanella strains. For example, Shewanella putrefaciens W3-18-1 (Sediment; under $630 \mathrm{~m}$ of oxic water) has been identified to contain two functional nap gene clusters (nap- $\alpha$ and $n a p-\beta)$, and the nitrate respiration in W3-18-1 starts earlier than that in MR-1 (with nap- $\beta$ only) under microoxic conditions (Qiu et al., 2013). In another Shewanella strain, Shewanella violacea DSS12 (Sediment; 5,110 m), it possesses more terminal oxidases with different affinities for oxygen and less terminal reductases, implying that DSS12 has undergone respiratory adaptation to aerobiosis in the upper layer of deep sea sediments (Aono et al., 2010).

The physiological results concerning the possession of two DMSO respiration systems in WP3 are quite different from those of the two NAP systems in WP3. Although two nitrate respiration systems (nap- $\alpha$ and nap- $\beta$ ) were identified in the WP3 genome, further studies demonstrated that WP3 possessing nap- $\alpha$ alone was more competitive than the strain possessing both nap- $\alpha$ and nap- $\beta$ during nitrate-dependent growth. Thus containing a single nap- $\alpha$ system should be the evolutionary direction for Shewanella to thrive at low temperature (Chen et al., 2011). By combining these results, we conclude that WP3 can utilize different strategies to evolve its different anaerobic respiration systems in response to deep sea environments.

The effects of pressure on the respiratory systems has been well studied in S. violacea DSS12. Although very few terminal reductases for anaerobic respiration being identified in DSS12 genome, it processes at least five sets of putative terminal oxidases for aerobic respiration (Aono et al., 2010), in which the expression of cytochrome $b d$ (quinol oxidase) was enhanced under high pressure (Tamegai et al., 2005). In addition, the $d$-type terminal oxidase of DSS12 was identified to be pressure-resistant and functional under high pressure conditions (Chikuma et al., 2007). Further research demonstrated that the piezotolerance of the Shewanella terminal oxidase activity perhaps depends on the intrinsic properties of the enzymes themselves but not their membrane lipid composition (Tamegai et al., 2011). In contrast, the piezophilic property of terminal oxidases in Photobacterium profundum SS9 (amphipod; 2,500 m) seems to be different. For one thing, the cytochrome content of $P$. profundum SS9 was not affected by altered pressure during growth; for another, genes encoding cytochromes showed no significant change in expression under different pressures during growth of $P$. profundum SS9. However, the piezotolerance of $P$. profundum SS9 terminal oxidase activity could also be observed using cells grown under higher pressures (Tamegai et al., 2012). Collectively, piezophiles from distinct genus may choose different strategies in adaptating to high pressure.

More recently, the respective effects of temperature and pressure on $\mathrm{Fe}$ (III) reduction rates (FeRRs) and viability have been investigated in deep sea bacterium Shewanella profunda LT13a (sediment; 4,500 m; Picard et al., 2015). Results showed that FeRR increased linearly with temperature between 4 and $37^{\circ} \mathrm{C}$, while the highest FeRR was observed between 10 and $40 \mathrm{MPa}$ and then slightly decreased with increasing pressure (40-110 $\mathrm{MPa})$, indicating that the respiratory chain was not immediately affected by pressure (Picard et al., 2015). Under high pressure conditions, the significantly increased energy demand for cell maintenance of $S$. profunda LT13a may account for its decreased viability (Picard et al., 2015). Here we observed that DMSO-dependent growth can occur when WP3 is incubated in $4^{\circ} \mathrm{C} / 20 \mathrm{MPa}$ conditions (Figure 5E), suggesting that the energy demand of WP3 could still be fulfilled under in situ conditions with DMSO as the sole electron acceptor.

Because the transcription profiles of these two $d m s$ gene clusters vary significantly in response to pressure or temperature changes (Figure 4), it is important to elucidate the mechanism by which $d m s$ gene clusters are regulated. Previously, a mutant lacking the fur gene (encoding the ferric uptake regulator) was found to be severely deficient in DMSO respiration in WP3 (Yang et al., 2013), indicating that Fur was the $d m s$ gene cluster regulator. Moreover, cAMP receptor protein (CRP) was also found to directly regulate the expression of the $d m s$ gene cluster in S. oneidensis MR-1 (Zhou et al., 2013). We predicted the transcriptional regulation motifs of both $d m s$ gene clusters in WP3 and found similar CRP binding motifs (data not shown). Taken together, the presence of the CRP and Fur binding motifs might be an alternative regulatory strategy for WP3 to cope with pressure or temperature changes in a subtle regulatory mechanism. Investigation into this mechanism is currently underway and will be described as part of a separate report.

\section{CONCLUSION}

We have shown that two dms operons found in S. piezotolerans WP3 are functional in DMSO respiration. Both $d m s$ gene clusters 
are essential for the maximum growth of WP3 under low temperature and high pressure conditions; the type I system is essential for the ability of WP3 to thrive under in situ conditions $\left(4^{\circ} \mathrm{C} / 20 \mathrm{MPa}\right)$, whereas the type II system is more important under other stressful conditions (i.e., $4^{\circ} \mathrm{C} / 0.1 \mathrm{MPa}$ and $20^{\circ} \mathrm{C} / 20 \mathrm{MPa}$ ). Based on these data, we propose that multiple copies of $d m s$ gene clusters may confer a competitive advantage to the ability of WP3 to thrive under a broader range of environmental conditions. Thus, deep sea microorganism-mediated DMSO reduction may contribute to the global DMS cycle, which has been neglected in previous studies.

\section{AUTHOR CONTRIBUTIONS}

LX, HJ, and XX designed the study, analyzed the data. LX and YZ participated in the experiments. LX and HJ wrote the manuscript

\section{REFERENCES}

Allen, E. E., Facciotti, D., and Bartlett, D. H. (1999). Monounsaturated but not polyunsaturated fatty acids are required for growth of the deep-sea bacterium Photobacterium profundum SS9 at high pressure and low temperature. Appl. Environ. Microbiol. 65, 1710-1720.

Andreae, M. O. (1990). Ocean-atmosphere interactions in the global biogeochemical sulfur cycle. Mar. Chem. 30, 1-29. doi: 10.1016/03044203(90)90059-1

Aono, E., Baba, T., Ara, T., Nishi, T., Nakamichi, T., Inamoto, E., et al. (2010). Complete genome sequence and comparative analysis of Shewanella violacea, a psychrophilic and piezophilic bacterium from deep sea floor sediments. Mol. BioSyst. 6, 1216-1226. doi: 10.1039/c000396d

Asher, E. C., Dacey, J. W., Mills, M. M., Arrigo, K. R., and Tortell, P. D. (2011). High concentrations and turnover rates of DMS, DMSP and DMSO in Antarctic sea ice. Geophys. Res. Lett. 38:L23609. doi: 10.1029/2011GL049712

Bürgmann, H., Howard, E. C., Ye, W., Sun, F., Sun, S., Napierala, S., et al. (2007). Transcriptional response of Silicibacter pomeroyi DSS-3 to dimethylsulfoniopropionate (DMSP). Environ. Microbiol. 9, 2742-2755. doi: 10.1111/j.1462-2920.2007.01386.x

Burns, J. L., and DiChristina, T. J. (2009). Anaerobic respiration of elemental sulfur and thiosulfate by Shewanella oneidensis MR-1 requires psrA, a homolog of the phsA gene of Salmonella enterica serovar typhimurium LT2. Appl. Environ. Microbiol. 75, 5209-5217. doi: 10.1128/AEM.00888-09

Charlson, R. J., Lovelock, J. E., Andreae, M. O., and Warren, S. G. (1987). Oceanic phytoplankton, atmospheric sulphur, cloud albedo and climate. Nature 326, 655-661. doi: 10.1038/326655a0

Chen, Y., Wang, F., Xu, J., Mehmood, M. A., and Xiao, X. (2011). Physiological and evolutionary studies of NAP systems in Shewanella piezotolerans WP3. ISME J. 5, 843-855. doi: 10.1038/ismej.2010.182

Cheng, Y.-Y., Li, B.-B., Li, D.-B., Chen, J.-J., Li, W.-W., Tong, Z.-H., et al. (2013). Promotion of iron oxide reduction and extracellular electron transfer in Shewanella oneidensis by DMSO. PLoS ONE 8:e78466. doi: 10.1371/journal.pone.0078466

Chikuma, S., Kasahara, R., Kato, C., and Tamegai, H. (2007). Bacterial adaptation to high pressure: a respiratory system in the deep-sea bacterium Shewanella violacea DSS12. FEMS Microbiol. Lett. 267, 108-112. doi: 10.1111/j.15746968.2006.00555.x

Curson, A. R., Todd, J. D., Sullivan, M. J., and Johnston, A. W. (2011). Catabolism of dimethylsulphoniopropionate: microorganisms, enzymes and genes. Nat. Rev. Microbiol. 9, 849-859. doi: 10.1038/nrmicro2653

Edwards, R. A., Keller, L. H., and Schifferli, D. M. (1998). Improved allelic exchange vectors and their use to analyze 987P fimbria gene expression. Gene 207, 149-157. doi: 10.1016/s0378-1119(97)00619-7 and XX critically reviewed the manuscript. All authors read and approved the final manuscript.

\section{FUNDING}

This work was financially supported by the National Natural Science Foundation of China (Grant No. 31290232), the China Ocean Mineral Resources R \& D Association (Grant No. DY12522-04), and the National Natural Science Foundation of China (Grant No. 41306129, 91228201, 91428308).

\section{SUPPLEMENTARY MATERIAL}

The Supplementary Material for this article can be found online at: http://journal.frontiersin.org/article/10.3389/fmicb. 2016.01418

Fredrickson, J. K., Romine, M. F., Beliaev, A. S., Auchtung, J. M., Driscoll, M. E., Gardner, T. S., et al. (2008). Towards environmental systems biology of Shewanella. Nat. Rev. Microbiol. 6, 592-603. doi: 10.1038/nrmicro1947

Froelich, P. N., Klinkhammer, G., Bender, M. A. A., Luedtke, N., Heath, G. R., Cullen, D., et al. (1979). Early oxidation of organic matter in pelagic sediments of the eastern equatorial Atlantic: suboxic diagenesis. Geochim. Cosmochim. Acta 43, 1075-1090. doi: 10.1016/0016-7037(79)90095-4

Gao, H., Yang, Z. K., Wu, L., Thompson, D. K., and Zhou, J. (2006). Global transcriptome analysis of the cold shock response of Shewanella oneidensis MR1 and mutational analysis of its classical cold shock proteins. J. Bacteriol. 188, 4560-4569. doi: 10.1128/jb.01908-05

Gralnick, J. A., Vali, H., Lies, D. P., and Newman, D. K. (2006). Extracellular respiration of dimethyl sulfoxide by Shewanella oneidensis strain MR-1. Proc. Natl. Acad. Sci. U.S.A. 103, 4669-4674. doi: 10.1073/pnas.0505959103

Hatton, A., Malin, G., Turner, S., and Liss, P. (1996). "DMSO: a significant compound in the biogeochemical cycle of DMS," in Biological and Environmental Chemistry of DMSP and Related Sulfonium Compounds, eds R. P. Kiene, P. T. Visscher, M. D. Keller, and G. O. Kirst (New York, NY: Plenum Press), 405-412.

Hatton, A., Turner, S., Malin, G., and Liss, P. (1998). Dimethylsulphoxide and other biogenic sulphur compounds in the Galapagos Plume. Deep Sea Res. Part 2 Top. Stud. Oceanogr. 45, 1043-1053. doi: 10.1016/s0967-0645(98)00017-4

Hatton, A. D., Darroch, L., and Malin, G. (2005). "The role of dimethylsulphoxide in the marine biogeochemical cycle of dimethylsulphide," in Oceanography and Marine Biology: An Annual Review, eds R. N. Gibson, R. J. A. Atkinson, and J. D. M. Gordon (Boca Raton, FL: CRC Press).

Hatton, A. D., Malin, G., and Liss, P. S. (1999). Distribution of biogenic sulphur compounds during and just after the southwest monsoon in the Arabian Sea. Deep Sea Res. Part 2 Top. Stud. Oceanogr. 46, 617-632. doi: 10.1016/s09670645(98)00120-9

Hau, H. H., and Gralnick, J. A. (2007). Ecology and biotechnology of the genus Shewanella. Annu. Rev. Microbiol. 61, 237-258. doi: 10.1146/annurev.micro.61.080706.093257

Jonkers, H. M., Der Maarel, M. J., Gemerden, H., and Hansen, T. A. (1996). Dimethylsulfoxide reduction by marine sulfate-reducing bacteria. FEMS Microbiol. Lett. 136, 283-287. doi: 10.1111/j.1574-6968.1996.tb08062.x

Li, S., Xiao, X., Sun, P., and Wang, F. (2008). Screening of genes regulated by cold shock in Shewanella piezotolerans WP3 and time course expression of cold-regulated genes. Arch. Microbiol. 189, 549-556. doi: 10.1007/s00203-0070347-1

Lubitz, S. P., and Weiner, J. H. (2003). The Escherichia coli ynfEFGHI operon encodes polypeptides which are paralogues of dimethyl sulfoxide reductase (DmsABC). Arch. Biochem. Biophys. 418, 205-216. doi: 10.1016/j.abb.2003.08.008 
McCrindle, S. L., Kappler, U., and McEwan, A. G. (2005). Microbial dimethylsulfoxide and trimethylamine-N-oxide respiration. Adv. Microb. Physiol. 50, 147-198. doi: 10.1016/s0065-2911(05)50004-3

Moran, M. A., Reisch, C. R., Kiene, R. P., and Whitman, W. B. (2012). Genomic insights into bacterial DMSP transformations. Annu. Rev. Mar. Sci. 4, 523-542. doi: 10.1146/annurev-marine-120710-100827

Muyzer, G., and Stams, A. J. (2008). The ecology and biotechnology of sulphatereducing bacteria. Nat. Rev. Microbiol. 6, 441-454. doi: 10.1038/nrmicro1892

Nealson, K. H., and Scott, J. (2006). "Ecophysiology of the genus Shewanella," in The Prokaryotes, ed. M. Dworkin (New York, NY: Springer), 1133-1151.

Orcutt, B. N., Sylvan, J. B., Knab, N. J., and Edwards, K. J. (2011). Microbial ecology of the dark ocean above, at, and below the seafloor. Microbiol. Mol. Biol. Rev. 75, 361-422. doi: 10.1128/mmbr.00039-10

Picard, A., Testemale, D., Wagenknecht, L., Hazael, R., and Daniel, I. (2015). Iron reduction by the deep-sea bacterium Shewanella profunda LT13a under subsurface pressure and temperature conditions. Front. Microbiol. 5:796. doi: $10.3389 /$ fmicb. 2014.00796

Qiu, D., Wei, H., Tu, Q., Yang, Y., Xie, M., Chen, J., et al. (2013). Combined genomics and experimental analyses of respiratory characteristics of Shewanella putrefaciens W3-18-1. Appl. Environ. Microbiol. 79, 5250-5257. doi: 10.1128/aem.00619-13

Rellinger, A. N., Kiene, R. P., del Valle, D. A., Kieber, D. J., Slezak, D., Harada, H., et al. (2009). Occurrence and turnover of DMSP and DMS in deep waters of the Ross Sea, Antarctica. Deep Sea Res. Part 1 Oceanogr. Res. Pap. 56, 686-702. doi: 10.1016/j.dsr.2008.12.010

Simó, R. (1998). Trace chromatographic analysis of dimethyl sulfoxide and related methylated sulfur compounds in natural waters. J. Chromatogr. A 807, 151-164. doi: 10.1016/s0021-9673(98)00086-7

Spiese, C. E., Kieber, D. J., Nomura, C. T., and Kiene, R. P. (2009). Reduction of dimethylsulfoxide to dimethylsulfide by marine phytoplankton. Limnol. Oceanogr. 54, 560-570. doi: 10.4319/lo.2009.54.2.0560

Stanley, N. R., Sargent, F., Buchanan, G., Shi, J., Stewart, V., Palmer, T., et al. (2002). Behaviour of topological marker proteins targeted to the Tat protein transport pathway. Mol. Microbiol. 43, 1005-1021. doi: 10.1046/j.1365-2958.2002.02797.x

Sunda, W., Kieber, D. J., Kiene, R. P., and Huntsman, S. (2002). An antioxidant function for DMSP and DMS in marine algae. Nature 418, 317-320. doi: 10.1038/Nature00851

Süß, J., Herrmann, K., Seidel, M., Cypionka, H., Engelen, B., and Sass, H. (2008). Two distinct Photobacterium populations thrive in ancient Mediterranean sapropels. Microb. Ecol. 55, 371-383. doi: 10.1007/s00248-007-9282-6

Tamegai, H., Kawano, H., Ishii, A., Chikuma, S., Nakasone, K., and Kato, C. (2005). Pressure-regulated biosynthesis of cytochrome bd in piezo-and psychrophilic deep-sea bacterium Shewanella violacea DSS12. Extremophiles 9, 247-253. doi: 10.1007/s00792-005-0439-2

Tamegai, H., Nishikawa, S., Haga, M., and Bartlett, D. H. (2012). The respiratory system of the piezophile Photobacterium profundum SS9 grown under various pressures. Biosci. Biotechnol. Biochem. 76, 1506-1510. doi: 10.1271/bbb.120237

Tamegai, H., Ota, Y., Haga, M., Fujimori, H., Kato, C., Nogi, Y., et al. (2011). Piezotolerance of the respiratory terminal oxidase activity of the piezophilic Shewanella violacea DSS12 as compared with non-piezophilic Shewanella species. Biosci. Biotechnol. Biochem. 75, 919-924. doi: 10.1271/bbb.100882
Thauer, R. K., Jungermann, K., and Decker, K. (1977). Energy conservation in chemotrophic anaerobic bacteria. Bacteriol. Rev. 41, 100-180.

Trieber, C. A., Rothery, R. A., and Weiner, J. H. (1996). Engineering a novel ironsulfur cluster into the catalytic subunit of Escherichia coli dimethyl-sulfoxide reductase. J. Biol. Chem. 271, 4620-4626. doi: 10.1016/s0167-7012(97)00990-1

Venkateswaran, K., Moser, D. P., Dollhopf, M. E., Lies, D. P., Saffarini, D. A., MacGregor, B. J., et al. (1999). Polyphasic taxonomy of the genus Shewanella and description of Shewanella oneidensis sp. nov. Int. J. Syst. Bacteriol. 49, 705-724. doi: 10.1099/00207713-49-2-705

Wang, F., Wang, J., Jian, H., Zhang, B., Li, S., Wang, F., et al. (2008). Environmental adaptation: genomic analysis of the piezotolerant and psychrotolerant deep-sea iron reducing bacterium Shewanella piezotolerans WP3. PLoS ONE 3:e1937. doi: 10.1371/journal.pone.0001937

Wang, F., Wang, P., Chen, M., and Xiao, X. (2004). Isolation of extremophiles with the detection and retrieval of Shewanella strains in deep-sea sediments from the west Pacific. Extremophiles 8, 165-168. doi: 10.1007/s00792-003-0365-0

Wang, F., Xiao, X., Ou, H.-Y., Gai, Y., and Wang, F. (2009). Role and regulation of fatty acid biosynthesis in the response of Shewanella piezotolerans WP3 to different temperatures and pressures. J. Bacteriol. 191, 2574-2584. doi: 10.1128/jb.00498-08

Wood, P. M. (1981). The redox potential for dimethyl sulphoxide reduction to dimethyl sulphide. FEBS Lett. 124, 11-14. doi: 10.1016/0014-5793(81) 80042-7

Xiao, X., Wang, P., Zeng, X., Bartlett, D. H., and Wang, F. (2007). Shewanella psychrophila sp. nov. and Shewanella piezotolerans sp. nov., isolated from west Pacific deep-sea sediment. Int. J. Syst. Evol. Microbiol. 57, 60-65. doi: 10.1099/ijs.0.64500-0

Yang, X.-W., He, Y., Xu, J., Xiao, X., and Wang, F.-P. (2013). The regulatory role of ferric uptake regulator (Fur) during anaerobic respiration of Shewanella piezotolerans WP3. PLoS ONE 8:e75588. doi: 10.1371/journal.pone.0075588

Yang, X.-W., Jian, H.-H., and Wang, F.-P. (2015). pSW2, a novel low-temperatureinducible gene expression vector based on a filamentous phage of the deep-sea bacterium Shewanella piezotolerans WP3. Appl. Environ. Microbiol. 81, 55195526. doi: 10.1128/aem.00906-15

Yayanos, A. A., and Van Boxtel, R. (1982). Coupling device for quick highpressure connections to $100 \mathrm{MPa}$. Rev. Sci. Instrum. 53, 704-705. doi: 10.1063/1. 1137011

Zhou, G., Yin, J., Chen, H., Hua, Y., Sun, L., and Gao, H. (2013). Combined effect of loss of the caa3 oxidase and Crp regulation drives Shewanella to thrive in redoxstratified environments. ISME J. 7, 1752-1763. doi: 10.1038/ismej.2013.62

Conflict of Interest Statement: The authors declare that the research was conducted in the absence of any commercial or financial relationships that could be construed as a potential conflict of interest.

Copyright (c) 2016 Xiong, Jian, Zhang and Xiao. This is an open-access article distributed under the terms of the Creative Commons Attribution License (CC BY). The use, distribution or reproduction in other forums is permitted, provided the original author(s) or licensor are credited and that the original publication in this journal is cited, in accordance with accepted academic practice. No use, distribution or reproduction is permitted which does not comply with these terms. 